\title{
Reclassification of Sulfolobus hakonensis Takayanagi et al. 1996 as Metallosphaera hakonensis comb. nov. based on phylogenetic evidence and DNA $\mathrm{G}+\mathrm{C}$ content
}

\author{
Norio Kurosawa, ${ }^{1}$ Yuko H. Itoh ${ }^{2}$ and Takashi Itoh ${ }^{3}$ \\ 1,2Departments of Environmental Engineering for Symbiosis ${ }^{1}$ and Bioinformatics ${ }^{2}$, Faculty of \\ Engineering, Soka University, 1-236 Tangi-cho, Hachioji, Tokyo 192-8577, Japan \\ ${ }^{3}$ Japan Collection of Microorganisms, RIKEN (The Institute of Physical and Chemical \\ Research), 2-1 Hirosawa, Wako, Saitama 351-0198, Japan
}

\begin{abstract}
The taxonomic status of Sulfolobus hakonensis Takayanagi et al. 1996 was re-evaluated by fresh determinations of the 16S rDNA sequence and $G+C$ content of the genomic DNA of the type strain, $\mathrm{HO} 1-1^{\top}$. The $16 \mathrm{~S}$ rDNA sequence of strain $\mathrm{HO} 1-1^{\top}$ showed $98 \%$ similarity to those of two Metallosphaera species and only $\leqslant 92 \%$ similarity to those of other Sulfolobus species. The DNA G + C content $(46 \cdot 2 \mathrm{~mol} \%)$ is in accordance with those of Metallosphaera species. In addition, strain $\mathrm{HO} 1-1^{\top}$ shares some phenotypic properties with Metallosphaera species; however, it can be differentiated from them by its capacity to utilize FeS and tetrathionate and the absence of flagella. Therefore, it is proposed that Sulfolobus hakonensis should be transferred to the genus Metallosphaera as Metallosphaera hakonensis comb. nov.
\end{abstract}

Sulfolobus hakonensis was proposed by Takayanagi et al. (1996) for a thermoacidophilic organism isolated from a hot spring in Ohwaku-dani, Hakone, Kanagawa, Japan. Strain HO $1-1^{\mathrm{T}}$ is the sole reported member of the species and was described as a lobe-shaped coccus, thriving under strictly aerobic and thermoacidophilic conditions $(\mathrm{pH} 3 \cdot 0$ and $70{ }^{\circ} \mathrm{C}$ ) and with a $\mathrm{G}+\mathrm{C}$ content of genomic DNA of $38.4 \mathrm{~mol} \%$. In addition to these properties, the presence of calditoglycerocaldoarchaeol and the phylogenetic position deduced from the 16S rDNA sequence suggested its placement in the order Sulfolobales (Takayanagi et al., 1996). When the species was proposed, the order Sulfolobales (family Sulfolobaceae) was composed of only four genera, Acidianus, Desulfurolobus, Metallosphaera and Sulfolobus. Among these genera, the monospecific genus Desulfurolobus was reclassified to the genus Acidianus (Fuchs et al., 1996). The remaining three genera could be distinguished by, for example, their capacity for anaerobic growth and the $\mathrm{G}+\mathrm{C}$ content of genomic DNA as follows: Acidianus, facultative anaerobes with 30-33 mol\% G+C; Metallosphaera, strict aerobes with $45-47 \mathrm{~mol} \% \mathrm{G}+\mathrm{C}$; Sulfolobus, strict aerobes with 34-39 mol\% G+C. Takayanagi et al. (1996) therefore regarded strain $\mathrm{HO} 1-1^{\mathrm{T}}$ as a member of the genus Sulfolobus and compared it with other Sulfolobus species

Published online ahead of print on 11 April 2003 as DOI 10.1099/ ijs.0.02716-0.

The GenBank/EMBL/DDBJ accession number for the $16 \mathrm{~S}$ rDNA sequence of strain $\mathrm{HO} 1-1^{\top}$ is D86414.
(Sulfolobus acidocaldarius, Sulfolobus solfataricus, Sulfolobus shibatae and Sulfolobus metallicus) to justify their proposal of the species S. hakonensis.

More recently, as a number of $16 \mathrm{~S}$ rRNA/DNA sequences of archaeal strains, including those of the order Sulfolobales, have become available, phylogenetic analysis has revealed that the currently described species of the genus Sulfolobus can be separated into at least three branches that may correspond to different genera (Fuchs et al., 1996; Huber \& Stetter, 2001). One branch includes the type species, $S$. acidocaldarius, another includes $S$. solfataricus and S. shibatae, while the third is represented by S. metallicus. In addition, Sulfolobus hakonensis is placed in the vicinity of Metallosphaera sedula (Huber et al., 1989) and Metallosphaera prunae (Fuchs et al., 1995).

In an attempt to re-evaluate the taxonomic status of the species S. hakonensis, we determined almost the entire $16 \mathrm{~S}$ rDNA sequence (1461 bp) and the $\mathrm{G}+\mathrm{C}$ content of the genomic DNA of the type strain, HO1-1 ${ }^{\mathrm{T}}$ (a generous gift from S. Takayanagi). The DNA base composition was estimated by the HPLC method of Tamaoka \& Komagata (1984). The 16S rDNA sequence we determined (accession no. D86414) is essentially identical to that reported previously (accession no. D14052), but the ambiguous bases (40 positions) of the previously reported sequence were resolved. The new $16 \mathrm{~S}$ rDNA sequence of HO1-1 $1^{\mathrm{T}}$ showed $98 \%$ similarity to those of the two Metallosphaera species, but showed very low similarity to the other members of 


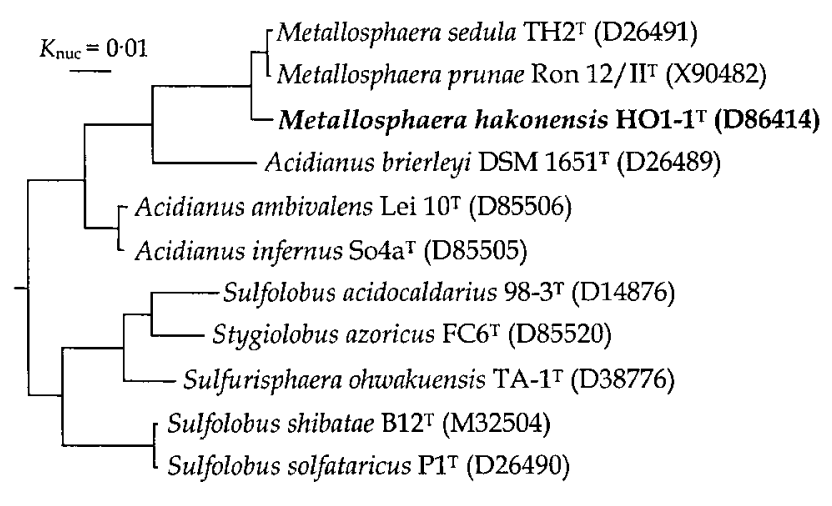

Fig. 1. Phylogenetic tree based on $16 \mathrm{~S}$ rDNA sequences. The tree was constructed by the maximum-likelihood method (Felsenstein, 1981) using the PHYLIP program (Felsenstein, 1993). Strain and sequence accession numbers (in parentheses) are indicated. The crenarchaeon Aeropyrum pernix $\mathrm{K}^{\top}$ (accession no. D83259) was used as the outgroup. All sites with gaps in any sequences were removed from the alignment that was used for estimating pairwise distances. A total of 1391 positions were used for construction of the phylogenetic tree.

the order Sulfolobales $(\leqslant 92 \%)$. On a phylogenetic tree constructed by the maximum-likelihood method (Felsenstein, 1981), strain $\mathrm{HO} 1-1^{\mathrm{T}}$ is clustered with the two Metallosphaera species (Fig. 1). The tree topology, particularly the position of strain $\mathrm{HO} 1-1^{\mathrm{T}}$, was identical to that of a previous tree (Huber \& Stetter, 2001) and was also supported by the neighbour-joining method (Saitou \& Nei, 1987) (not shown). On the other hand, the $G+C$ content of the genomic DNA determined by us was $46 \cdot 2 \mathrm{~mol} \%$ (originally reported as $38 \cdot 4 \mathrm{~mol} \%$ ). It is thought that the difference (about $8 \mathrm{~mol} \%$ ) between our result and the earlier one originates from the different methods used. The G + C content presented by Takayanagi et al. (1996) was estimated by the $\mathrm{CsCl}$ isopycnic centrifugation method, which is much less accurate than the HPLC method. The new value for the $\mathrm{G}+\mathrm{C}$ content of strain $\mathrm{HO} 1-1^{\mathrm{T}}$ is again closer to those of Metallosphaera species than to known Sulfolobus species $(34 \cdot 6-42 \cdot 0 \mathrm{~mol} \%)$. In agreement with the two Metallosphaera species, strain $\mathrm{HO} 1-1^{\mathrm{T}}$ is a strictly aerobic, facultative chemolithotroph that grows optimally at around $70-75^{\circ} \mathrm{C}$ and $\mathrm{pH}$ 3. Strain $\mathrm{HO} 1-1^{\mathrm{T}}$ and the two Metallosphaera species utilize complex organic substances such as yeast extract, but not sugars, as carbon sources. Thus, on the basis of the phylogenetic and phenotypic properties described above, it is evident that strain $\mathrm{HO} 1-1^{\mathrm{T}}$ belongs to the genus Metallosphaera. Strain HO1-1 ${ }^{\mathrm{T}}$ and the two Metallosphaera species also utilize elemental sulfur and several reduced sulfur compounds as energy sources: however, strain $\mathrm{HO} 1-1^{\mathrm{T}}$ additionally utilizes $\mathrm{FeS}$ and tetrathionate, unlike the two Metallosphaera species.
Strain $\mathrm{HO} 1-1^{\mathrm{T}}$ does not have flagella, while $M$. prunae does. Therefore, strain $\mathrm{HO} 1-1^{\mathrm{T}}$ represents a species separate from the two Metallosphaera species and we propose a new combination, Metallosphaera hakonensis (Takayanagi et al. 1996) comb. nov., with the type strain HO1-1 ${ }^{\mathrm{T}}$.

\section{Description of Metallosphaera hakonensis comb. nov.}

Metallosphaera hakonensis (ha.ko.nen'sis. N.L. fem. adj. hakonensis pertaining to Hakone, Japan, where the type strain was isolated).

Basonym: Sulfolobus hakonensis Takayanagi et al. 1996.

The description is the same as that given for Sulfolobus hakonensis (Takayanagi et al., 1996) except for the DNA $\mathrm{G}+\mathrm{C}$ content of the type strain, which is $46 \cdot 2 \mathrm{~mol} \%$. The new accession number for the 16S rRNA gene of the type strain is D86414. The type strain, HO1-1 ${ }^{\mathrm{T}}$, is deposited in several culture collections as IAM $14250^{\mathrm{T}}$, JCM $8857^{\mathrm{T}}$, DSM $7519^{\mathrm{T}}$ and ATCC $51241^{\mathrm{T}}$.

\section{References}

Felsenstein, J. (1981). Evolutionary trees from DNA sequences: a maximum likelihood approach. J Mol Evol 17, 368-376.

Felsenstein, J. (1993). PHYLIP (phylogeny inference package) version 3.5c. Distributed by the author. Department of Genetics, University of Washington, Seattle, USA.

Fuchs, T., Huber, H., Teiner, K., Burggraf, S. \& Stetter, K. O. (1995). Metallosphaera prunae, sp. nov., a novel metal-mobilizing, thermoacidophilic Archaeum, isolated from a uranium mine in Germany. Syst Appl Microbiol 18, 560-566.

Fuchs, T., Huber, H., Burggraf, S. \& Stetter, K. O. (1996). $16 \mathrm{~S}$ rDNA-based phylogeny of the archaeal order Sulfolobales and reclassification of Desulfurolobus ambivalens as Acidianus ambivalens comb. nov. Syst Appl Microbiol 19, 56-60.

Huber, H. \& Stetter, K. O. (2001). Genus I. Sulfolobus Brock, Brock, Belly and Weiss 1972, 66 ${ }^{\mathrm{AL}}$. In Bergey's Manual of Systematic Bacteriology, 2nd edn, vol. 1, The Archaea and the Deeply Branching and Phototrophic Bacteria, pp. 198-202. Edited by D. R. Boone, R. W. Castenholz \& G. M. Garrity. New York: Springer.

Huber, G., Spinnler, C., Gambacorta, A. \& Stetter, K. O. (1989). Metallosphaera sedula gen. nov. and sp. nov. represents a new genus of aerobic, metal-mobilizing, thermoacidophilic archaebacteria. Syst Appl Microbiol 12, 38-47.

Saitou, N. \& Nei, M. (1987). The neighbor-joining method: a new method for reconstructing phylogenetic trees. Mol Biol Evol 4, 406-425.

Takayanagi, S., Kawasaki, H., Sugimori, K., Yamada, T., Sugai, A., Ito, T., Yamasato, K. \& Shioda, M. (1996). Sulfolobus hakonensis sp. nov., a novel species of acidothermophilic archaeon. Int $J$ Syst Bacteriol 46, 377-382.

Tamaoka, J. \& Komagata, K. (1984). Determination of DNA base composition by reversed phase high-performance liquid chromatography. FEMS Microbiol Lett 25, 125-128. 